\title{
Fingerprint Minutiae Matching without Global Alignment Using Local Structures
}

\author{
Andrej KISEL, Alexej KOCHETKOV, Justas KRANAUSKAS \\ Department of Computer Science II, Faculty of Mathematics and Informatics, Vilnius University \\ e-mail: justas@atrodo.com
}

Received: April 2007

\begin{abstract}
This paper presents a method of minutiae based fingerprint matching that is robust to deformations and does not do fingerprint alignment. It concentrates on comparing rotation and translation invariant local structures defined by minutiae point and its neighboring minutiae points. Then the collection of most probable correspondences of matched minutiae is found. Finally, the local structures of higher order are validated. All three steps are completely rotation and translation invariant, robust to nonlinear deformations and do not use any fingerprint alignment. Experimental results on publicly available as well as internal databases show an improved performance of the proposed method in comparison with the traditional minutiae based algorithms that perform fingerprint registration.
\end{abstract}

Key words: alignment, fingerprint identification, local structures, minutiae matching.

\section{Introduction}

Most automatic fingerprint verification/identification systems use minutiae information from fingerprints to align and compare images or their templates to speed up the matching process. We refer to minutiae as ridge ending or ridge bifurcation with any additional local features in this paper. Extraction of minutiae from fingerprint image is out of the scope of this paper.

Much effort has been made to create matching algorithms capable of dealing with distortion and deformations in fingerprint images. Overview of possible methods is made in (Maltoni et al., 2003). Thin-plate spline model is used to deal with distortion (Bazen et al., 2002): first, local matching is performed on structures that consist of minutiae and its two closest neighboring minutiae points to determine witch minutiae possibly match, then global matching is made to find registration parameters; after finding the global registration parameters that coarsely align two fingerprints, elastic deformation is eliminated using thin-plate spline model, and final match is made. The authors reported major increase in performance. However, their approach uses registration estimation that is not reliable with distorted fingerprints since accurate registration does not often exist. Fig. 1 demonstrates two fingerprints taken from the same finger, after alignment. There is a region in both fingerprints, that is not distorted, but major deformations exist in other areas of fingerprints, because fingers are soft and elastic. 


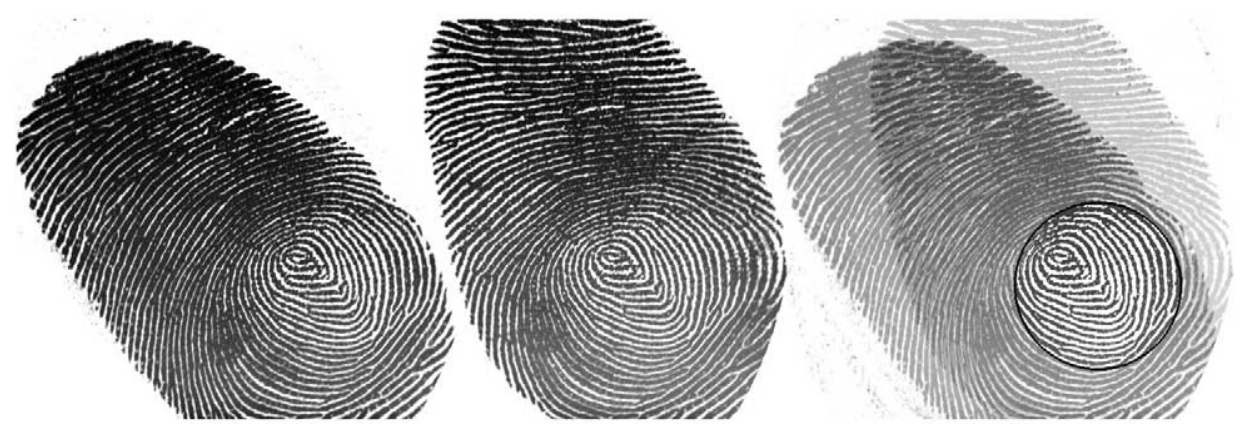

Fig. 1. Two different impressions of the same fingerprint before and after registration.

Errors in registration lead to errors in further steps. Matching based on local and global structures is described in (Ratha et al., 2000). Local matching uses local structures that consist of minutiae point and its neighboring minutiae points and is rotation and translation tolerant. Local structures from both fingerprints are matched to find the best matching pair. This pair is used as a reference correspondence point, and other minutiae points are aligned based on this correspondence. After alignment global structure matching is done. To account for deformation, large bounding boxes are used, but to decrease the probability of false match, the matching certainty level function that provides some sort of match probability instead of just "matched" or "not matched" result is defined. Although authors reported good matching performance, the disadvantages of their matching algorithm are similar to (Bazen et al., 2002). If the fingerprints are distorted, the exact registration parameters do not exist, and even the reference local pair cannot be used to align them. Errors in choosing the right reference point or incorrect alignment lead to incorrect match. Other methods are described in literature (Maltoni et al., 2003), but most of them are either variations of above described methods that use registration, or their computational cost is too high or they use some other, not minutiae methods to deal with distortion and can not be used with existing fingerprint databases based on minutiae. For example, interesting method is introduced in (Senior and Bolle, 2001), where authors normalize the fingerprint image to a canonical form so that ridges are equally spaced and less affected by distortion. In (Capelli et al., 2001) a distortion model that could describe elastic deformation found in fingerprint images is presented. Authors validated it by manually setting deformation parameters, but no automatic optimization technique that could be used to automatically derive deformation parameters while matching minutiae is known. In general, distortion elimination is a hard problem that could improve performance of most matchers, if properly solved. After normalization or deformation removal a rigid matcher could be used for direct comparison (Malickas and Vitkus, 1999). Another normalization technique was introduced in (Lee et al., 2002) - the minutiae distance is normalized at the matching stage according to the local ridge frequency. This method could improve matcher performance for good quality fingerprints where reliable frequency estimation is possible, and for minutiae pairs that are not far from one another, so that changes in ridge frequency along the fingerprint that occurs even in not distorted images are less than errors that are made while estimating the frequency. 
In this paper, a completely new approach of minutiae matching is proposed as a framework with broad range of possible implementations. One of the most simple but effective implementation is discussed here. The method consists of three main steps: matching of local structures, correspondence set construction and validation of higher order local structures. The first step has the following properties:

- low false rejection ratio (FRR);

- rotation and translation invariance;

- locality (for tolerance to deformations);

- low computational complexity.

Possible implementation will be discussed in Section 2. The second step receives a similarity matrix filled with similarity score of every minutiae point from the first template compared with every minutiae point from the second template. In spite of the fact, that one minutiae point from the first template can be very similar to several different minutiae points from the second template, every minutiae point can make only one correspondence between the templates. Construction of minutiae correspondence set is discussed in Section 3. While constructing the minutiae correspondence set no information about the global fingerprint structure is used. The last step of global fingerprint structure validation is discussed in Section 4.

\section{Local Matching}

In most general case, template of fingerprint is the description of minutiae points set. Two sets of minutiae must be compared while matching two fingerprints. For simplicity, we will call $T$ (test set) - the first set of $N$ minutiae and $S$ (sample set) - the second set of $M$ minutiae. The order of sets is not important because the proposed method is symmetric. We define local matching as a comparison of $N$ local structures from set $T$ to $M$ local structures from set $S$ where every local structure is associated with minutiae which serves as a reference point to that local structure. The result of local matching step is an $N \times M$ similarity matrix filled with similarities between local structures.

\subsection{Local Structure}

Generally, local structure could be anything from a minutiae point identified by a vector starting at $(x, y)$ and local ridge direction $\phi$ to a set of minutiae with some portions of original image. However, we are looking for a structure having the following characteristics:

- rotation and translation invariance,

- locality (for tolerance to deformations),

- fast and easy comparable.

One of possible candidate could be the structure that we define using graph notation similar to (Ratha et al., 2000), see Fig. 2. The local structure associated with the minutiae 


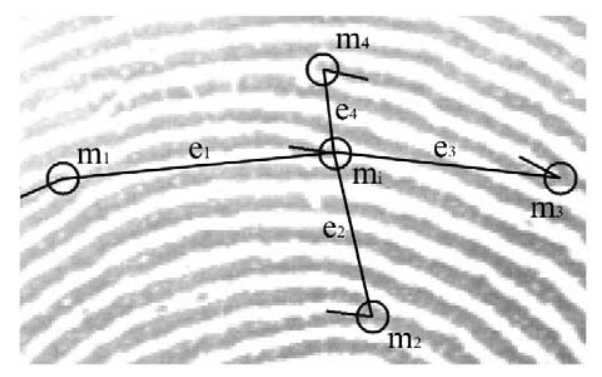

Fig. 2. Local structure associated with minutiae $m_{i}$.

$m_{i}$ (defined by a vector starting at $\left(x_{i}, y_{i}\right)$ and local ridge direction $\left.\phi_{i}\right)$ for some distance $d_{\max }$ and maximum number of nearest neighbors $n_{\max }$ is the graph $S_{i}=\left(V_{i}, E_{i}\right)$ consisting of:

- $V_{i}=\left\{m_{j} \mid\right.$ distance $\left.\left(m_{i}, m_{j}\right)<d_{\max }\right\},\left|V_{i}\right| \leqslant n_{\max }$;

- $E_{i}=\left\{e_{i j} \mid e_{i j}\right.$ connects $m_{i}$ and $\left.m_{j}\right\}$, where $e_{i j}$ is labeled with tuple ( $i, j$, distance $\left.(i, j), \phi_{i j}\right), \phi_{i j}$ is the angle between $m_{i}$ and $m_{j}$ directions. Additionally, other features can be used to improve the performance.

Such local structure is rotation and translation invariant and tolerant to non rigid nonlinear deformations.

\subsection{Similarity Score}

In spite of the fact, that minutiae extraction from fingerprint image is out of the scope of this paper, possible errors of false detected and missed minutiae cannot be ignored. The local structures cannot be compared directly if any of these errors is present. To deal with these errors we construct a similarity function $C S\left(S_{i}^{T}, S_{j}^{S}\right)$ for comparison of two local structures $S_{i}^{T}$ and $S_{j}^{S}$ from test and sample fingerprints. If there were no extraction errors the edges of every local structure could be sorted in clockwise (or counterclockwise order) starting from the direction of associated minutiae and compared directly by a function

$$
\begin{aligned}
& C S\left(S_{i}^{T}, S_{j}^{S}\right)=\sum_{k=1}^{\left|E_{i}^{T}\right|} C E\left(e_{i k}^{T}, e_{j k}^{S}\right), \\
& C E\left(e_{i k}^{T}, e_{j k}^{S}\right)=\left\{\begin{array}{l}
0, \quad \text { if } \Delta d \geqslant \Delta d_{\max } \text { or } \Delta \varphi \geqslant \Delta \varphi_{\max } \\
w_{d} \frac{\Delta d_{\max }-\Delta d}{\Delta d_{\max }}+w_{\varphi} \frac{\Delta \varphi_{\max }-\Delta \varphi}{\Delta \varphi_{\max }}, \quad \text { otherwise. }
\end{array}\right. \\
& \Delta d=\left|\operatorname{distance}\left(m_{i}^{T}, m_{k}^{T}\right)-\operatorname{distance}\left(m_{j}^{S}, m_{k}^{S}\right)\right|, \\
& \Delta \varphi=\min \left(\left|\varphi_{i}-\varphi_{j}\right|, 2 \pi-\left|\varphi_{i}-\varphi_{j}\right|\right), \\
& \Delta d_{\max }, \Delta \varphi_{\max }, w_{d}, w_{\varphi}-\text { predefined parameters. }
\end{aligned}
$$


However, we can deal with errors introduced by extraction in the following way:

- sort $E_{i}^{T}$ edges in a clockwise order (starting from the direction of associated minutiae) into a sequence $E v_{i}^{T}$;

- sort $E_{j}^{S}$ edges in a clockwise order (starting from the direction of associated minutiae) into a sequence $E v_{j}^{S}$;

- find the longest common subsequence (LCS) of $E v_{i}^{T}$ and $E v_{j}^{S}$ using the same similarity function $C E$ from (2) for comparison of sequences elements;

- sum up the similarities of edges that make the longest common subsequence:

$$
C S^{\prime}\left(S_{i}^{T}, S_{j}^{S}\right)=\sum_{e_{i k}^{T}, e_{j l}^{S} \in L C S\left(E v_{i}^{T}, E v_{j}^{S}\right)} C E\left(e_{i k}^{T}, e_{j l}^{S}\right) .
$$

As a convenient abuse of terminology we will use $C S$ instead of $C S^{\prime}$ to represent similarity between two local structures.

\section{Correspondence Set Construction}

After calculating similarity between every local structure from test and sample fingerprints similarity matrix $S M_{N \times M}$ is filled with these values. This matrix can be used to construct a correspondence set of minutiae pairs where every local structure belongs maximum to one correspondence:

$$
C=\left\{\left(S_{i}^{T}, S_{j}^{S}\right) \mid S_{i}^{T} \in T, S_{j}^{S} \in S\right\}, \quad|C| \leqslant \min (N, M) .
$$

Though many different approaches can be used to find minutiae correspondence set, a maximum weighted matching on bipartite graphs will be used to find the correspondence set maximizing the sum of similarities between local structures.

Bipartite graph is constructed from similarity matrix with vertices defined by local structures from both fingerprints and weighted edges defined by greater than 0 similarities between associated local structures. We use Hungarian algorithm to solve this problem in $\mathrm{O}\left(\max (N, M)^{3}\right)$ time in worst case.

\section{Validation}

Until a correspondence set is constructed no global fingerprint registration is used and for robustness to deformations it will not be used anywhere in the proposed method. Although local structures from test and sample fingerprints can have high similarity they can be situated differently in respect to each other in fingerprints (see Fig. 3). Local structures $\mathbf{1}_{\mathrm{t}}$ and $\mathbf{1}_{\mathrm{s}}, \mathbf{2}_{\mathrm{t}}$ and $\mathbf{2}_{\mathrm{s}}, \mathbf{3}_{\mathrm{t}}$ and $\mathbf{3}_{\mathrm{s}}$ seem alike. Each of them has two neighbors, and distances to them are similar, but when edges $\mathbf{b}_{\mathbf{t}}$ and $\mathbf{b}_{\mathbf{s}}$ are examined, it is obvious that they are different (if we align structures $\mathbf{1}_{\mathrm{t}}$ and $\mathbf{1}_{\mathrm{s}}, \mathbf{3}_{\mathrm{t}}$ and $\mathbf{3}_{\mathrm{s}}$, we will notice, that 


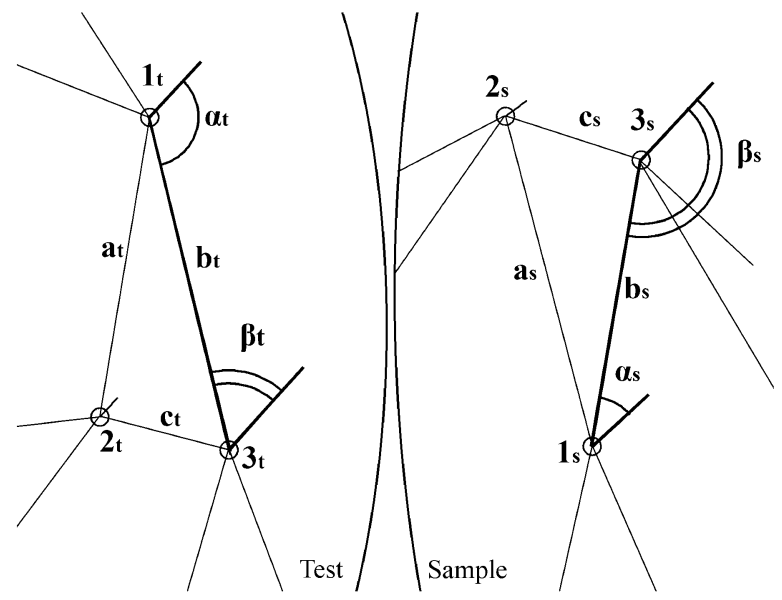

Fig. 3. Corresponding local structures (numbered $\mathbf{1}_{\mathrm{t}}$ and $\mathbf{1}_{\mathrm{s}}, \mathbf{2}_{\mathrm{t}}$ and $\mathbf{2}_{\mathrm{s}}, \mathbf{3}_{\mathrm{t}}$ and $\mathbf{3}_{\mathrm{s}}$ ).

although lengths of edges $\mathbf{b}_{\mathbf{t}}$ and $\mathbf{b}_{\mathbf{s}}$ are similar, the corresponding angles $\boldsymbol{\alpha}_{\mathbf{t}}$ and $\boldsymbol{\alpha}_{\mathbf{s}}$ are quite different, and pointing the opposite direction, so are the angles $\boldsymbol{\beta}_{\mathbf{t}}$ and $\boldsymbol{\beta}_{\mathbf{s}}$.

Similar cases should be taken under consideration. The easiest solution would be global alignment of fingerprints. Since we do not use any global registration (many fingerprints are distorted), local structures of higher order can be used to control how local structures are located in the fingerprint. We define the local structures of higher order as any pair of local structures from correspondence set $C=\left\{\left(c_{T}^{i}, c_{S}^{i}\right),|1 \leqslant i \leqslant| C \mid\right\}$ constructed in previous section for test and sample fingerprints:

$$
\begin{aligned}
& H S_{i j}^{T}=\left(c_{i}^{T}, c_{j}^{T}\right), \quad 1 \leqslant i<j \leqslant|C|, \\
& H S_{i j}^{S}=\left(c_{i}^{S}, c_{j}^{S}\right), \quad 1 \leqslant i<j \leqslant|C| .
\end{aligned}
$$

Local structures of higher order $H S_{i j}^{T}$ and $H S_{i j}^{S}$ are rotation and translation invariant. Additionally, they hold information on how local structures are situated in the fingerprint in respect of each other without a need of global fingerprint registration. Some of the local structures of higher order are illustrated in Fig. 3 marked by Latin letters $\mathbf{a}_{\mathbf{t}}$ and $\mathbf{a}_{\mathbf{s}}, \mathbf{b}_{\mathbf{t}}$ and $\mathbf{b}_{\mathbf{s}}, \mathbf{c}_{\mathbf{t}}$ and $\mathbf{c}_{\mathbf{s}}$. For example, structure $\mathbf{b}_{\mathbf{t}}$ (identified by local structures $\mathbf{1}_{\mathbf{t}}$ and $\mathbf{3}_{\mathbf{t}}$, angles $\boldsymbol{\alpha}_{\mathrm{t}}$ and $\boldsymbol{\beta}_{\mathrm{t}}$, and distance between minutiae associated with local structures) from Fig. 3 in test fingerprint is compared to corresponding structure $\mathbf{b}_{\mathbf{s}}$ in sample fingerprint. If the structures are not consistent they are not used in calculating similarity score between fingerprints. 


\subsection{Similarity Score}

We define similarity score $S S$ between two local structures of higher order $H S_{i j}^{T}$ and $H S_{i j}^{S}$ as

$$
S S\left(H S_{i j}^{T}, H S_{i j}^{S}\right)=\left\{\begin{array}{l}
0, \quad \text { if } \Delta l \geqslant \Delta l_{\max } \text { or } \Delta \alpha \geqslant \Delta \alpha_{\max } \text { or } \Delta \beta \geqslant \Delta \alpha_{\max } \\
w_{l} \frac{\Delta l_{\max }-\Delta l}{\Delta l_{\max }}+w_{\alpha} \frac{\Delta \alpha_{\max }-\Delta \alpha}{\Delta \alpha_{\max }}+w_{\alpha} \frac{\Delta \alpha_{\max }-\Delta \beta}{\Delta \alpha_{\max }}, \quad \text { otherwise. }
\end{array}\right.
$$

$m_{i}^{T}, m_{j}^{T}, m_{i}^{S}, m_{j}^{S}-$ minutiae associated with local structures from $H S_{i j}^{T}$ and $H S_{i j}^{S}$,

$\Delta l=\mid$ distance $\left(m_{i}^{T}, m_{j}^{T}\right)-\operatorname{distance}\left(m_{i}^{S}, m_{j}^{S}\right) \mid$,

$\Delta \alpha=\min \left(\left|\alpha^{T}-\alpha^{S}\right|, 2 \pi-\left|\alpha^{T}-\alpha^{S}\right|\right)$,

$\alpha^{T}, \alpha^{S}, \beta^{T}, \beta^{S}$ - angles between the segments connecting the local structures of higher order and directions of their associated minutiae,

$\Delta \beta=\min \left(\left|\beta^{T}-\beta^{S}\right|, 2 \pi-\left|\beta^{T}-\beta^{S}\right|\right)$,

$\Delta d_{\max }, \Delta \alpha_{\max }, w_{l}, w_{\alpha}$ - predefined parameters.

If similarity is 0 , the pair of matched local structures of higher order is rejected and does not participate in final similarity calculation (does not pass the validation step).

\subsection{Global Similarity Score}

We define similarity score between two fingerprints as a sum of similarity scores between all local structures of higher order (that passed a validation step) combined with similarity scores of local structures that make them:

$$
S C O R E=\frac{\sum_{i, j} f\left(S S\left(H S_{i j}^{T}, H S_{i j}^{S}\right), C S\left(S_{i}^{T}, S_{i}^{S}\right), C S\left(S_{j}^{T}, S_{j}^{S}\right)\right)}{g(N, M)},
$$

where $S_{i}^{T}, S_{i}^{S}, S_{j}^{T}, S_{j}^{S}$ are local structures that make $H S_{i j}^{T}$ and $H S_{i j}^{S}$,

$f\left(S S\left(H S_{i j}^{T}, H S_{i j}^{S}\right), C S\left(S_{i}^{T}, S_{i}^{S}\right), C S\left(S_{j}^{T}, S_{j}^{S}\right)\right)$ can be one of the following (but not limited to):

$$
\begin{aligned}
& S S\left(H S_{i j}^{T}, H S_{i j}^{S}\right)+\frac{C S\left(S_{i}^{T}, S_{i}^{S}\right)+C S\left(S_{j}^{T}, S_{j}^{S}\right)}{2} \\
& S S\left(H S_{i j}^{T}, H S_{i j}^{S}\right) \cdot C S\left(S_{i}^{T}, S_{i}^{S}\right) \cdot C S\left(S_{j}^{T}, S_{j}^{S}\right) \\
& S S\left(H S_{i j}^{T}, H S_{i j}^{S}\right) \sqrt{C S\left(S_{i}^{T}, S_{i}^{S}\right) \cdot C S\left(S_{j}^{T}, S_{j}^{S}\right)}
\end{aligned}
$$

$g(N, M)$ function is used to normalize similarity score for differently sized fingerprints.

Selection of the most suitable $f$ and $g$ functions is left for the future work. $f$ function from Eq. (9) and $g$ function equal to $N$ and $M$ product were used during evaluation. 


\section{Evaluation}

\subsection{Description of the Proposed Implementation}

We will refer to our implementation of the proposed fingerprint minutiae matching framework as Local Structure Matcher (LSM). The following brief sequence of steps summarizes current implementation:

- construction of local structures (Subsection 2.1),

- matching of local structures (Subsection 2.2),

- correspondence set construction (Section 3),

- validation of correspondences by using local structures of higher order (Section 4),

- calculation of final similarity score (Subsection 4.2).

\subsection{Threshold Parameters in Local Structures}

Two threshold parameters are used in constructing local structures $-d_{\max }$ and $n_{\max }$. Experimental results show that changing value of parameter $d_{\max }$ hardly changes matching performance. However, to make structures more local the value of 150 pixels was chosen. Additional testing was performed on several databases for choosing the value of $n_{\text {max }}$ parameter. It showed that $n_{\max }$ is a tradeoff between speed and quality. The quality is measured as FRR at FAR $0.01 \%$. FAR (the probability that a biometric system will incorrectly identify an individual) and FRR (the probability that a biometric system will fail to identify an enrolled individual) are calculated according to FVC2002 protocol (Maio et al., 2002). The results are shown in Fig. 4. The value of 10 was chosen.

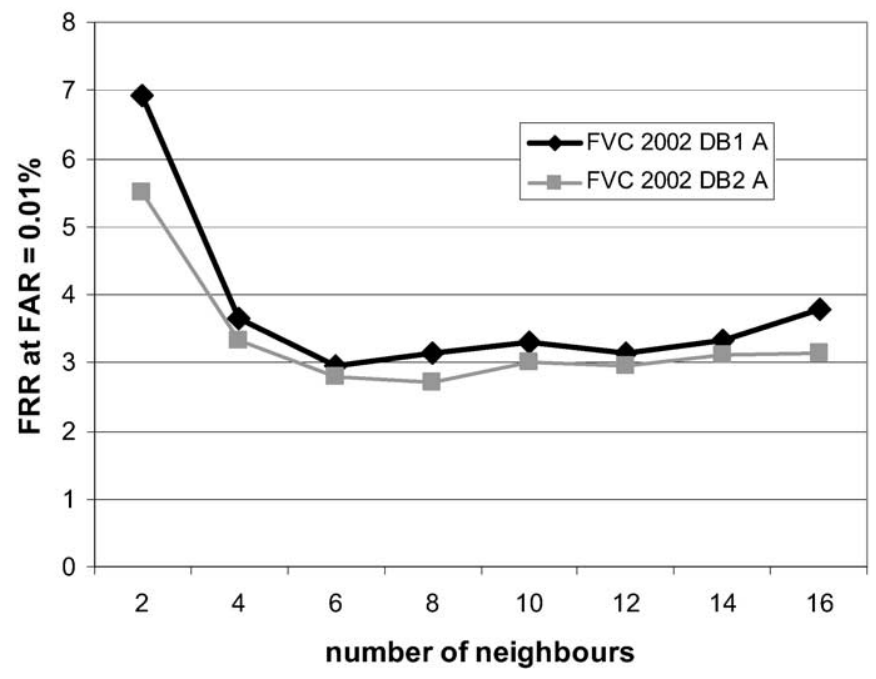

Fig. 4. Change of FRR at FAR $0.01 \%$ (in percents) for different values of $n_{\text {max }}$ on different databases. 


\subsection{Threshold Parameters in Similarity Functions}

The proposed method uses several predefined thresholds $\left(\Delta d_{\max }, \Delta \varphi_{\max }, \Delta l_{\max }\right.$, $\Delta \alpha_{\text {max }}$ ), however we show that similarity functions are constructed to be robust. None of them uses a hard decision (see (2), (6), and (7)) because the information on level of similarities is lost in that way. Our similarity functions include this information and are stable in respect to varying values of threshold parameters. Actually, these parameters control what amount of deformation is allowed by the proposed method. For example, allowing stronger deformations (higher thresholds values) results in higher false acceptance rates but lower false rejection rate. The parameters we used $\left(\Delta d_{\max }=12, \Delta \varphi_{\max }=17^{\circ}\right.$, $\Delta l_{\max }=12, \Delta \alpha_{\max }=17^{\circ}$ ) was a compromise between FAR and FRR.

Actual values of parameters were obtained by modifying similarity functions so that a hard decision in similarity calculation (6) is made (the similarity of matched structures is considered zero if difference in distances, or angles, or other properties are above the thresholds, and equals 1 if differences in all properties are below the thresholds). Optimal values were obtained by manual adjustment of parameters to minimize FAR and FRR errors on different databases. When optimal hard decision threshold values where calculated, similarity functions were modified to make soft decision (6) (contrary to hard decision similarity function, similarity of matched structures equals to differences in measured properties scaled to interval [0..1]).

Additional testing showed that the chosen values can be changed within $\pm 50 \%$ without noticeable impact to the performance of the proposed method.

\subsection{Performance Evaluation}

To show the performance of the proposed method it was tested on publicly available NIST Special Database 29 (Watson, 2001) fingerprint database (hereafter referred as SD29). The database consists of 216 ten-print fingerprint card pairs with both the rolled and plains scanned at 19.7 pixels per mm. For direct comparison we chose publicly available NIST fingerprint image software NFIS2 (Watson et al., 2002) minutiae based fingerprint matching algorithm (hereafter referred as BOZORTH3). Fingerprint minutiae extractor from NFIS2 (MINDTCT) was not used in the evaluation because of big number of false minutiae it produces (BOZORTH3 matcher uses only 150 minutiae of best quality from the fingerprint template to deal with this problem). We tested the proposed matching method with commercially available fingerprint minutiae extraction algorithm of better quality (Neurotechnologija, 2006) (hereafter referred as COMM).

SD29 database consists only of fingerprint images that were scanned from fingerprint cards. Additional tests were done to prove that the proposed method works well with live scanned fingerprints. The following databases were chosen:

- DB1 from FVC2002 fingerprint verification competition (Maio et al., 2002) collected with optical sensor "TouchView II" from Identix. The database consists of 800 different fingerprints with 8 impressions per finger. 
- DB2 from FVC2002 fingerprint verification competition collected with optical sensor optical sensor "FX2000" from Biometrika. The database consists of 800 different fingerprints with 8 impressions per finger.

- Neurotechnologija's internal database collected with optical single-finger scanner "DFR 2090" from Identix (hereafter referred as INTERNAL1). The database consists of 1400 different fingerprints with 10 impressions per finger.

- Neurotechnologija's internal database collected with high-quality optical singlefinger scanner "Cross Match Verifier 300" (hereafter referred as INTERNAL2) recommended for large scale automatic fingerprint identification systems. The database consists of 1400 different fingerprints with 10 impressions per finger.

\section{Results}

NIST VTB fingerprint system with Bozorth98 matcher (previous version of BOZORTH3) participated in Fingerprint Vendor Technology Evaluation (FpVTE) 2003 (Wilson et al., 2004) and proved to be comparable to other commercial algorithms and even better than almost half of the contestants. The following experiment shows an improvement of the proposed method over BOZORTH3 matcher with COMM minutiae extractor. 18 ROC curves were calculated on different parts of SD29 (Watson et al., 2005) for every method. SD29 consists of rolled and plain fingerprints taken from different fingers. Parts of database are named: RT (right thumb), LT(left thumb), RI(right index), LI(left index), RM(right middle), LM(left middle). Since both rolled ant plain versions of fingerprints are present in database, algorithm tolerance to fingerprint deformation (observable on rolled fingerprints) can be evaluated. The results are shown in Table 1 and Table 2. Columns correspond to different parts of database, and rows correspond to different matching scenario: P2P (plain fingerprints are matched with plain fingerprints), $\mathrm{P} 2 \mathrm{R}$ (plain fingerprints are matched with rolled fingerprints), R2R (rolled fingerprints are matched with rolled fingerprints)

The proposed method improves FRR at FAR $=0.01 \%$ from $12.01 \%$ to $9.20 \%$ on average. As expected, the largest improvement was gained on rolled-to-rolled fingerprint matching were stronger deformations of fingerprints are possible.

Fig. 5 and Fig. 6 show the performance of the proposed method on live scan fingerprints from FVC2002 databases that were collected with optical scanners.

Table 1

COMM+BOZORTH3 FRR at FAR $0.01 \%$ on different parts of SD29

\begin{tabular}{rrrrrrrr}
\hline Part & RT & LT & RI & LI & RM & LM & Average \\
\hline P2P & 7.1 & 6.2 & 18.9 & 15.0 & 14.8 & 14.1 & 12.68 \\
P2R & 12.7 & 12.8 & 14.7 & 18.6 & 14.6 & 12.2 & 14.27 \\
R2R & 16.3 & 11.3 & 6.6 & 5.9 & 8.3 & 6.0 & 9.08 \\
\hline
\end{tabular}


Table 2

COMM+ LSM FRR at FAR $0.01 \%$ on different parts of SD29

\begin{tabular}{cccccccc}
\hline Part & RT & LT & RI & LI & RM & LM & Average \\
\hline P2P & 7.14 & 9.89 & 14.8 & 11.5 & 15.9 & 13.2 & 12.07 \\
P2R & 5.36 & 9.34 & 9.07 & 12.5 & 9.62 & 9.34 & 9.205 \\
R2R & 4.95 & 7.69 & 4.4 & 6.59 & 5.49 & 8.79 & 6.318 \\
\hline
\end{tabular}

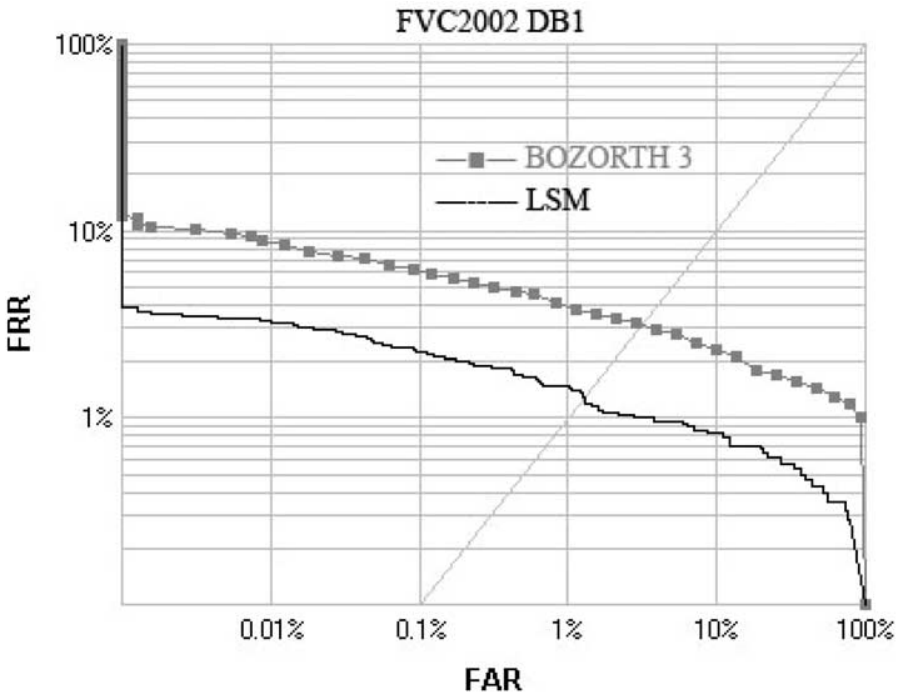

Fig. 5. COMM+BOZORTH3 compared to COMM+LSM on FVC2002 DB1 database.

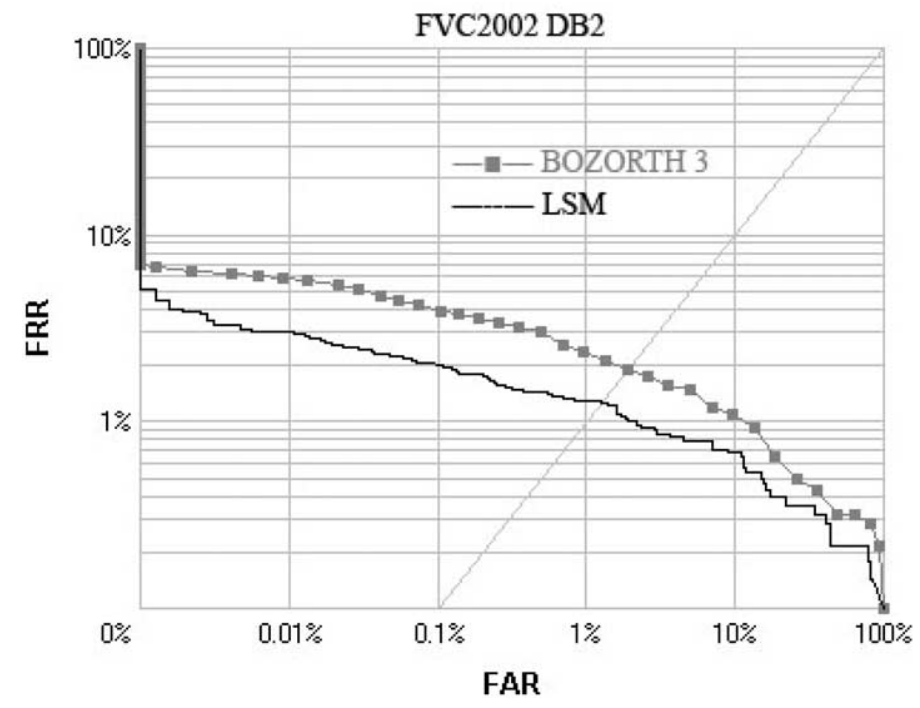

Fig. 6. COMM+BOZORTH3 compared to COMM+LSM on FVC2002 DB2 database. 
Table 3

FRR at FAR $0.01 \%$ on tested databases with commercial minutiae extractor

\begin{tabular}{lrl}
\hline \multicolumn{1}{c}{ Database } & BOZORTH3 & LSM \\
\hline SD29 (average) & $12.01 \%$ & $9.20 \%$ \\
FVC2002 DB1 & $8.73 \%$ & $3.29 \%$ \\
FVC2002 DB2 & $5.82 \%$ & $3.00 \%$ \\
INTERNAL1 & $5.65 \%$ & $2.3 \%$ \\
INTERNAL2 & $1.78 \%$ & $0.44 \%$ \\
\hline
\end{tabular}

Summary of improvements to FRR at FAR $=0.01 \%$ over all databases is presented in Table 3. The largest improvement was achieved for the live scanned fingerprints.

\section{Conclusion}

In this paper we have presented a framework to match deformed fingerprints. It consists of simple and intuitive steps. The proposed implementation of the steps is straightforward and flexible, does not use registration, and is capable of matching deformed fingerprints. It leaves much freedom in combining the suggested methods with other approaches. Evaluation of algorithm was made on large data sets with different matching parameters. It has been shown that proposed method is flexible and tolerant to rotation, translation and deformation of fingerprint images. Performance of the method was compared with BOZORTH3 matcher and improvements up to 4 times (one-tailed paired t-test; $p<0.0005$; Table 3) in false rejection rates at $0.01 \%$ FAR were demonstrated.

During developing and testing of the framework, minutiae features were limited to position and direction information. Addition of other features to improve matcher performance will be evaluated in the future.

\section{Acknowledgment}

We are grateful to Dr. A. Bastys and Dr. A. Malickas for valuable discussions on preparing this paper. We would also like to acknowledge Neurotechnologija (Neurotechnologija, 2006) who provided resources and support for developing the proposed method.

\section{References}

Bazen, A.M., and S.H. Gerez (2002). Thin-plate spline modelling of elastic deformations in fingerprints. In Proc. 3rd IEEE Benelux Signal Processing Symposium (SPS-2002). Leuven, Belgium.

Cappelli, R., D. Maio and D. Maltoni (2001). Modelling plastic distortion in fingerprint images. In Proceedings of the Second International Conference on Advances in Pattern Recognition. pp. 369-376.

Lee, D., K. Choi and J. Kim (2002). A robust fingerprint matching algorithm using local alignment. In Proc. 16th ICPR, Vol. 3. pp. 803-806. 
Maio, D., D. Maltoni, R. Cappelli, J.L. Wayman and A.K. Jain (2002). FVC2002: second fingerprint verification competition. In Proceedings 16th International Conference on Pattern Recognition (ICPR2002). Québec City, Vol. 3. pp. 811-814.

Malickas, A., and R. Vitkus (1999). Fingerprint registration using composite features consensus. Informatica, 10(4), 389-402.

Maltoni, D., D. Maio, A.K. Jain and S. Prabhakar (2003). Handbook of Fingerprint Recognition. Springer, New York.

Neurotechnologija MegaMatcher SDK (2006). http: / / www. neurotechnologija.com/mm_sdk.html.

Ratha, N.K., R.M. Bolle, V.D. Pandit and V. Vaish (2000). Robust fingerprint authentication using local structural similarity. In Fifth IEEE Workshop on. Applications of Computer Vision (WACV). Santa Barbara, CA. pp. 29-34.

Senior, A., and R. Bolle (2001). Improved fingerprint matching by distortion removal. IEICE Trans. Information and Systems, 84(7), 825-831.

Watson, C.I. (2001). NIST Special Database 29, Plain and Rolled Images from Paired Fingerprint Cards. U.S. National Institute of Standards and Technology.

Watson, C.I., M.D. Garris, E. Tabassi, C.L. Wilson, R.M. McCabe and S. Janet (2002). User's Guide to NIST Fingerprint Image Software 2 (NFIS2). National Institute of Standards and Technology.

Watson, C., C. Wilson, K. Marshall, M. Indovina and R. Snelick (2005). Studies of One-to-One Fingerprint Matching with Vendor SDK Matchers. National Institute of Standards and Technology.

Wilson, C., R.A. Hicklin, H. Korves, B. Ulery, M. Zoepfl, M. Bones, P. Grother, R. Michaels, S. Otto and C. Watson (2004). Fingerprint Vendor Technology Evaluation 2003: Summary of Results and Analysis Report. National Institute of Standards and Technology.

A. Kisel received his BS and MS degree in computer science from Vilnius University, Lithuania in 2003 and 2005 respectively. He is currently a PhD student in Vilnius University. His research interests include fingerprint recognition, image processing and synthetic fingerprint generation. From 2002 till now he is a research scientist at "Neurotechnologija".

A. Kochetkov received the BS and MS degrees in engineering informatics from Vilnius Gediminas Technical University, Lithuania, in 2003 and 2005 respectively. He is currently a PhD student at Vilnius University. From 2002 till now he is a research scientist at "Neurotechnologija" in fingerprint recognition field.

J. Kranauskas received the BS and MS degrees in computer science from Vilnius University, Lithuania, in 2003 and 2005 respectively. He is currently a PhD student at Vilnius University. His research interests include pattern recognition, graph theory, real-time image processing, machine vision and learning. 


\section{Pirštu atspaudu palyginimas pagal taškinius požymius naudojant lokalias struktūras be globalios transformacijos atstatymo}

Andrej KISEL, Alexej KOCHETKOV, Justas KRANAUSKAS

Straipsnyje pristatomas naujas pirštų atspaudụ lyginimo pagal taškinius požymius metodas, kuris yra atsparus deformacijoms, nes neatlieka globalaus pirštu atspaudu išlygiavimo. Aprašomas metodas naudoja lokalias posūkiui ir poslinkiui invariantiškas struktūras, kurios yra sudarytos iš taškiniu požymiu ir ju artimiausiu kaimynu. Pristatomas labiausiai tikètinų lokaliu struktūru poru išrinkimas ir iš ju sudaromu aukštesnès eilès struktūru pakartotinis patikrinimas. Visi naujo metodo žingsniai yra invariantiški posūkiui ir poslinkiui, o taip pat yra atsparūs pirštu atspaudu deformacijoms. Atliktais eksperimentais su viešai prieinamomis duomenu bazėmis parodoma, kaip pagerèja pirštu atspaudu atpažinimo kokybe, jeigu pasiūlytas metodas naudojamas vietoje tradiciniu globalu pirštų atspaudų išlygiavimą atliekančių metodų. 